\title{
Downhole geophysical observatories: best installation practices and a case history from Turkey
}

\author{
Bernhard Prevedel · Fatih Bulut • Marco Bohnhoff • \\ Christina Raub · Recai F. Kartal · Fatih Alver • \\ Peter E. Malin
}

Received: 4 April 2014 / Accepted: 22 January 2015 / Published online: 7 February 2015

(c) The Author(s) 2015. This article is published with open access at Springerlink.com

\begin{abstract}
Downhole sensors of different types and in various environments provide substantial benefit to signal quality. They also add the depth dimension to measurements performed at the Earths' surface. Sensor types that particularly benefit from downhole installation due to the absence of near-surface noise include piezometers, seismometers, strainmeters, thermometers, and tiltmeters. Likewise, geochemical and environmental measurements in a borehole help eliminate near-surface weathering and cultural effects. Installations from a few hundred meter deep to a few kilometer deep dramatically reduce surface noise levels - the latter noticeably also reduces the hypocentral distance for shallow microearthquakes. The laying out of a borehole network is always a compromise of local boundary conditions and the involved drilling costs. The installation depth and procedure for a long-term downhole observatory can range from time limited installations, with a retrieval option, to permanently cemented sensors.
\end{abstract}

B. Prevedel $(\bowtie) \cdot$ F. Bulut $\cdot$ M. Bohnhoff $\cdot$ C. Raub

Helmholtz-Centre Potsdam GFZ German Centre for Geosciences,

Telegrafenberg, 14473 Potsdam, Germany

e-mail: prevedel@gfz-potsdam.de

Present Address:

F. Bulut

TÜBITAK Marmara Research Center, Gebze, Turkey

M. Bohnhoff

Department of Earth Sciences, Free University Berlin, Malteser

Strasse 74-100, 12249 Berlin, Germany

R. F. Kartal · F. Alver

AFAD, Disaster and Emergency Management Presidency,

Ankara, Turkey

P. E. Malin

IESE, University of Aukland, Aukland, New Zealand
Permanently cemented sensors have proven to be longterm stable with non-deteriorating coupling and borehole integrity. However, each type needs to be carefully selected and planned according to the research aims. A convenient case study is provided by a new installation of downhole seismometers along the shoreline of the eastern Marmara Sea in Turkey. These stations are being integrated into the regional net for monitoring the North Anatolian Fault Zone. Here we discuss its design, installation, and first results. We conclude that, despite the logistical challenges and installation costs, the superior quality of downhole data puts this technique at the forefront of applied and fundamental research.

Keywords Downhole observatory $\cdot$ Permanent monitoring $\cdot$ Seismometer $\cdot$ Fault system $\cdot$ North Anatolian Fault Zone $\cdot$ Earthquake research

\section{General aspects}

Downhole monitoring and intelligent well completions have initially been employed in offshore oil and gas wells. The International Ocean Drilling Program (IODP) has optimized science-driven subsea well completions by installing sensors for permanent operation in mid-ocean boreholes (Davis and Becker 2007). All of these downhole geophysical observatory installations required, as a minimum, a deployment system, the measurement sensors, a sensoranchoring system, and a data recording system.

Permanent Downhole Monitoring (PDM) installations on land have different challenges. In their current state of the art, there are two principle PDM designs available in industry and academia, both of which are mature enough to provide safe and reliable long-term monitoring operation 
in boreholes. These are (1) behind casing-installed sensor packages, facing the rock formation and permanently cemented in place, and (2) instruments deployed inside the casing or open hole, conveyed by pipe or wire rope and held in place by hole-locks or cement. In both cases, communication to the surface is done by means of electric wires or tube-enclosed optical fiber. Today, the type-1 behind casing installations can only be performed by a drill rig during the process of constructing a borehole, and sensor retrieval for repair or replacement can only be performed by the wire-line or pipe options of type- 2 combined with active hole-locks.

Common to all PDM installations, but in particular to the cemented type, is the need for a long downhole life expectancy in terms of system reliability and measurement repeatability. Therefore, emphasis has to be given in array designs toward redundancy of sensors and telemetry lines to avoid the risk of short-term failures. These specifications can vary depending on the measurement objectives and depth of installation. For common oil and gas applications, a minimum environmental specification target of $125^{\circ} \mathrm{C}$ at 500 bars for $+20.000 \mathrm{~h}$ continuous operation with a sensor drift of 0.04 units/year has been proposed by Algeroy et al. (2010). These limits provide good baselines from which typically more end-member academic specifications can be derived.

In analogy to intelligent oil and gas well completions, research PDM observatories have to be designed also with great care for best system efficiency, maximum life expectancy, and minimum interruption of the data production stream-and, typically, all of this at the lowest possible cost. The initial design process for a PDM array and its installation procedure revolves around two basic questions. First, will the observatory have sensors behind casing in order to allow wellbore access to other research activities and second, does it have to transmit data digitally to the surface or is analog signal sufficient? As described in the following sections, the subsequent planning steps flow from this choice.

\section{Deployment system}

A deployment or conveyance system is the means to transport the sensor packages in and out of a hole. It is usually also the instrument's supply lines to the surface. Every PDM system therefore requires a reliable deployment mechanism for its safe installation, uninterrupted operation, and, in the instance of a non-cemented completion, its safe retrieval to surface.

The most common and versatile way to deploy borehole instrumentation in a well is by means of a cable coming off from a drum of a cable spooling unit (Fig. 1a). The value of such an operation lies in its independence from any rig or special wellhead pulley support system.

Armored electric cables were originally developed for electric wire-line logging under very harsh conditions in the oil and gas drilling industry. They typically have $11 \mathrm{~mm}$ diameter and consist of an outer mechanical armor of two layers of counter-helically twisted steel wires and an inner core of individually insulated copper conductors wrapped in plastic jackets. Advanced cable technologies offer a core with six copper lines and one stainless steel tube containing several fiber optical lines (Thompson 1985). Cable designs with armors of stainless alloys or titanium and with several more conductors are also available. Some designs may include plastic-coated or silverplated armor depending on borehole temperature and corrosiveness of its fluids.

In 60 degrees-from-vertical or higher-deviated boreholes, instruments cannot be deployed on a standard wireline and special techniques are necessary to convey these tools downhole. Here, one solution is coiled tubing (CT). This setup consists of 15- to 30-mm-diameter continuous production tubing rolled on a large reel and with an optional armored wire-line cable installed inside of it to push well logging tools down into high-angle borehole sections (Fig. 1b). CT is fabricated from highly ductile steel alloy that recovers its initial strength even after being plastically deformed several times beyond yield. But this material has also a greatly reduced breaking stress level at lower fatigue cycles compared with high-graded steels. Therefore, the CT operational parameters have to be carefully monitored to avoid premature downhole failure (Rodriguez et al. 1998).

Another option for PDM installations is using drill pipe, casings, or production tubing as the conveyance system (Fig. 1c). For reasons of a costly drill rig required to perform such an operation, this method is today more linked with deep behind casing installations. But, it is equally common for permanent shallow installations, because of its ease of running the instrumentation and completing inhole cementation relatively inexpensive, quickly with much simpler rigging equipment (Fig. 1d). The GONAF borehole installations presented in this paper are of that type. In this deployment method, complex analog arrays or fiber optic systems are deployed by strapping their non-armored polyurethane cables at discrete intervals to the conveyance pipe. Cable clamping is done with steel bands that are best applied every $10-15 \mathrm{~m}$ to support the weight of the polyurethane cables and to avoid slippage and cable tear (Fig. 3, center). Careful planning and evaluation of cable weight, cable strength, and instrument buoyancy, combined with frequent clamping and sufficient rig time for the installation, is a good bases for achieving best field results (Prevedel et al. 2008). 


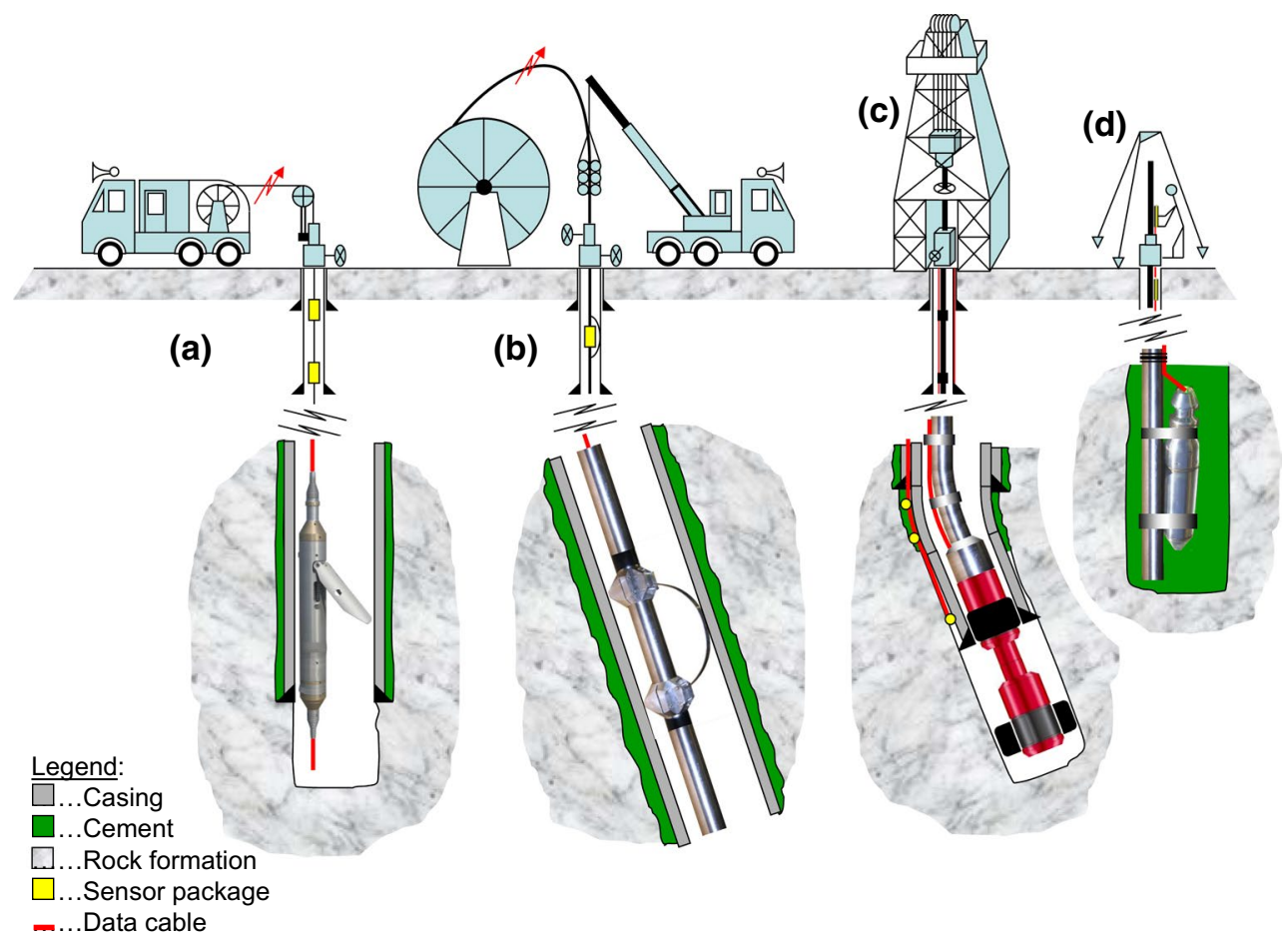

Fig. 1 PDM installations distinguished by their type of down-thehole conveyance method, a rope or cable, b coiled tubing, $\mathbf{c}$ and $\mathbf{d}$ pipe-or their downhole anchoring mechanism with a electrically

\section{Hole-anchoring systems}

Hole-locks are surface-activated devices that anchor PDM instruments firmly inside a cased or open-hole borehole section. They must assure that sensor coupling is not eroding with time and no relative motion of the instruments with respect to the borehole wall can take place over long monitoring periods. Different types of sensors require different qualities of anchoring mechanisms, which is classified by lock force-to-instrument weight ratio and by the duration of anchoring time. Typically, geo-mechanical measurements and seismic sensors require the highest holelocking quality. In contrast, geochemical and some electromagnetic sensors are almost insensitive to hole positioning and some sensors require no hole-lock at all.

Initially, anchoring devices were mostly based on mechanical bow-spring centralizers (Fig. 1b). This efficient concept consisted of a spring-steel bow that created enough friction on the side of the hole so that the tool would not move except by pulling on its cable. Enhanced designs include electrical or hydraulic actuators inside the downhole tool that extend bows or steel claw arms and release them again on command (Fig. 1a).

Mechanically or hydraulically inflatable packers are the most reliable and strongest hole-locking devices available for anchoring instruments firmly in the hole for very long activated lock arms, b bow-spring centralizers or de-centralizers, c mechanically/hydraulically activated packers or behind casing installations, and $\mathbf{d}$ permanently downhole cemented sensors

monitoring periods (Zoback et al. 2011). As they require rotational or hydraulic actuation downhole, they are almost entirely depending on CT or pipe conveyance. Releasing packers even after years of set time is almost uncritical due to the presence of pipes for applying the required pull-free force. Moreover, these devices can be set and released multiple times with virtually any lock force that is accepted by the borehole wall (Fig. 1c).

\section{Sensors}

The availability of sensors in industry and academia is actually quite large. Significant research and engineering effort has been conducted in the development of new technology, small-sized, and high-temperature-resistant sensors, and they generally divide themselves into (1) actively powered and (2) non-powered passive sensors.

Actively powered sensors require either external or internal power in order to take and relay measurements. Data are usually delivered with an integrated digital output so that an array of sensors can be easily connected with one single downhole network. Passive sensors on the other hand are either mechanical or optical devices that do not require external power supplies. They take measurements continuously and deliver an analog output signal. For this 
reason, each analog sensor requires its own dedicated transmission line to surface, resulting in case of a multisensor deployment to a sizeable signal cable or cable bundle that has to be supported by a logistically complex cable spooling operation at the well site.

The choice of sensor type depends on many conditions and is most of the time driven by the type of measurement sought, its signal quality, and resolution level. Other driving factors could be the desired number of measurement points in space, the expected life time of the array, and its temperature exposure downhole over the entire monitoring period, as well as their cost for packaging them into pressure housings to let them survive the harsh pressure and temperature conditions downhole.

The most frequently selected and considered PDM sensors are as follows:

- Seismic-geophone/seismometer, hydrophone, accelerometer, optical geophones;

- Geometric-tiltmeter, pendulums and fiber optic meters;

- Geo-mechanical-strainmeters and straingages, piezoand fiber optic stress meters;

- Environmental-distributed temperature sensing (DTS), pressure and temperature gauges, optical flow meters;

- Geochemical-gamma ray counter, downhole sample taking via U-tube, hydrologic measurements.

\section{Data telemetry, recording, and data management}

Prior to the digital era, data acquisition had to be done inside the downhole instrument and the tool had to be recovered to surface for data reading and interpretation. Today, data can be transmitted in analog or digital form from downhole to the surface. At some point in this transmission line, an analog/digital (A/D) converter has to be included so that data can be digitally recorded by a computer for processing and archiving. The selection where the data are converted, either downhole or at surface, is primarily driven by the length of the borehole network, by the total number of sensors downhole, the sensor resolution requirements, and cost. Because of the risk of a premature downhole electronic failure due to internal heat production at the circuit boards, downhole $\mathrm{A} / \mathrm{D}$ conversion is rather avoided for long-term PDM installations whenever possible. Hence, the safer and conservative approach for an uninterrupted long-term recording is to send the signals in analog form to the surface and perform the A/D conversion at the well site-recording cabin. Resistance along the long cables, however, might significantly reduce the voltage of analog signals that might need to be amplified in front of the digitizer in order to bring the signal up beyond the digitizer self-noise. Designs for field data acquisition stations depend on the type of measurement and data volume. These can range from small PC-based systems to large container-housed computer centers.

\section{Case histories: from the HRSN and Hi-net to GONAF}

In the USA and Japan, borehole installations have been successfully operated throughout the last decades. Much experience has been gained from these efforts. In particular, we refer to the local High Resolution Seismic Network (HRSN) on the San Andreas Fault (SAF) in California (Malin et al. 1989; Michelini and McEvilly 1991) and the Hi-net system covering all of Japan (Okada et al. 2004). Beginning in the mid-1980s, the HRSN seismometers were deployed at 16 sites in 100 - to $300-\mathrm{m}$ boreholes surrounding the Parkfield segment of the SAF. The Hi-net in Japan consists of over 700 sites of varying depth boreholes and downhole seismic sensors. Both installations have produced unique waveform recordings, providing state-of-theart seismological research for decades, demonstrating that the effort needed for implementing a PDM pays off on the long-term.

Experiences gained from these and other PDM networks have been incorporated in more recent networks, including for example the US Plate Boundary Observatory (NRC 2001). In the rest of this section, we will discuss how these lessons have been used in construction of the Geophysical Observatory of the North Anatolian Fault (GONAF) downhole network in northwestern Turkey (Bohnhoff et al. 2013). The GONAF net is focused on long-term earthquake monitoring along the Marmara segment of the NAFZ, immediately south of the city of Istanbul.

The NAFZ has produced several large $(M>7)$ earthquakes in the historic past. Since 1939, the fault zone has seen a remarkable sequence of westward propagating large earthquakes, leaving the Marmara Sea segment offshore of Istanbul as the only segment that has not moved since 1766 (e.g., Barka et al. 2002; Stein et al. 1997; Reilinger et al. 2000). Currently, there is a high probability for a major earthquake along the Princess Islands segment, $<20 \mathrm{~km}$ from the roughly 13 million people who live in Istanbul (Parsons 2004). GONAF is a joint research venture between GFZ Potsdam and the Turkish Disaster and Emergency Presidency (AFAD) in Ankara. It is co-funded by GFZ, AFAD, Turkish Ministry of Development, the International Scientific Drilling Program (ICDP), and the German Helmholtz Association (HGF). When completed, it will comprise an eight-station earthquake downhole observatory, each equipped with a fivestage array of seismometers in 300-m-deep boreholes.

The aim of this project is to monitor earthquake activity at the low magnitude-detection threshold and high 

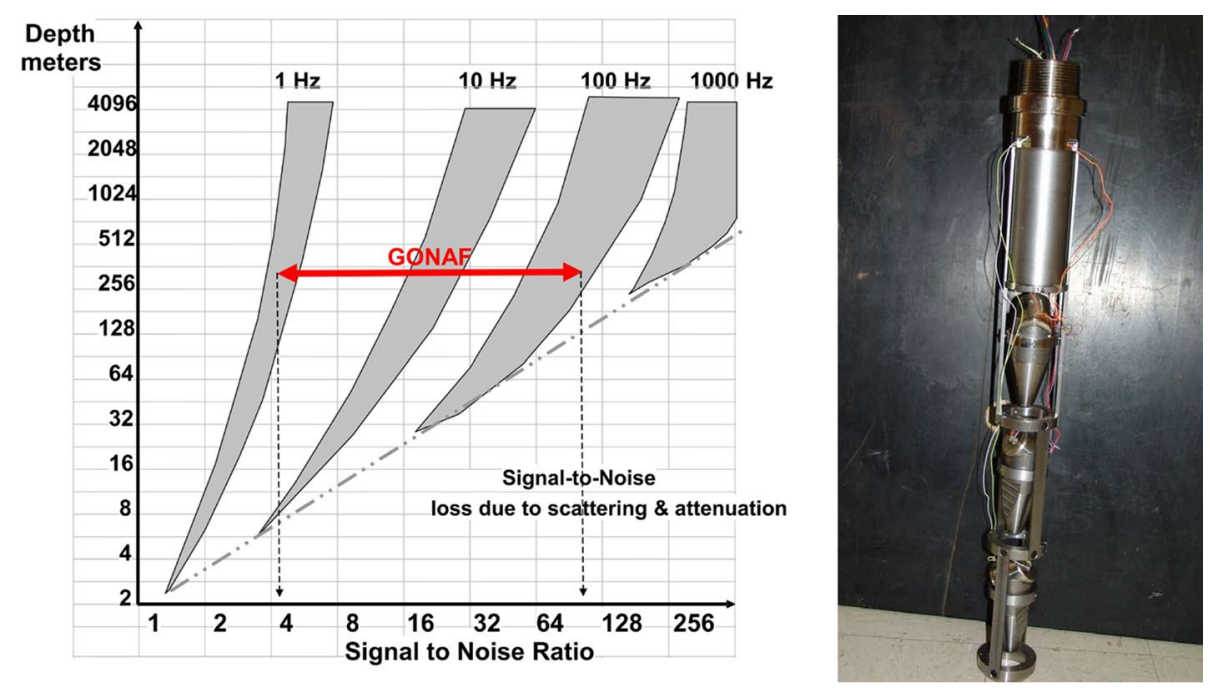

Fig. 2 Left anticipated noise attenuation and signal improvement with depth and type of sensor as proposed by P.E. Malin. The red arrow indicates the expected frequency band for microseismic recordings and subsequent improvements in signal-to-noise ratio with respect to surface for the downhole seismometers deployed in the frame of the GONAF project (see text for details). Right fully gim-

precision not achievable with surface recordings. The locations of these on-land stations were selected to be as close as possible to the offshore fault segment and will include two Princess Islands-based sites (Bohnhoff et al. 2013). Combined with data from the existing Princess Islands surface arrays (Bulut et al. 2009, 2011) and selected permanent regional stations, the GONAF net is expected to lower the local magnitude-detection threshold by at least one order of magnitude (Fig. 2, left). The project hopes thereby to provide new insights into the physical processes surrounding an $M \sim 7$ earthquake. It is also aimed at calibrating and refining ground shaking models, and nearreal-time hazard assessments for the megacity of Istanbul based on side effect studies that analyze waveforms from short-period instruments at different depth levels as well as broadband and strong-motion data recorded at the wellhead of each GONAF array.

The first three GONAF observatories were completed in 2012 to 2013, a test installation on the Tuzla Peninsula (eastern part of Istanbul) and two standardized sites on the Armutlu peninsula along the southern shore of the Marmara Sea.

\section{GONAF sensor and recorder selections}

Commonly, as discussed, the plan for a downhole seismometer installation is primarily driven by borehole diameter, temperature, geology, and tilt constraints. These in turn are driven by "upstream" factors such as drilling cost baled seismometer suspensions for 2-directional tilts, to be installed in a high-pressure housing filled with viscous damping fluid. The geophones embedded in carefully balanced counterweights shown are Geospace $57^{\circ}$ Gal'perin position HS-1 $4.5 \mathrm{~Hz}$ velocity sensors. The enclosed cylinder above these sensors contains a three-component (3-C) MEM accelerometer

and drill site access, and very rarely the other way around. The GONAF network in Turkey is one of the exceptions to these constraints, with the scientific aims specifying the borehole design and sensor selection.

For scientific wells, the borehole diameters can range from a few tens to a few hundreds of millimeters. With off-the-shelf sensors, temperature limits are at very most $\sim 175{ }^{\circ} \mathrm{C}$ in neutral aquifer water, falling below $\sim 100{ }^{\circ} \mathrm{C}$ in corrosive ones. Tilts can be a few degrees to more than 90, with wells claimed to be "vertical" typically deviating $5^{\circ}-15^{\circ}$. Knowing this value is important; for example, since it determines the lowest natural frequency, a spring/ moving coil seismometer can function within specifications-the latter being quoted at tilts $<1^{\circ} / 4^{\circ}$ for $1 \mathrm{~Hz}$ units-and whether or not they can be mounted in fixed positions or needed to be trunnioned or gimbaled (Fig. 2, right). The effect of both tilt and temperature on these sensors is a gradual change in natural frequency, linearity, and resonance frequencies, up until its suspended coils hit a mechanical motion limit. The lower the natural frequency, the worse this problem becomes and the more quickly the "stops" are reached.

The basic aim of the GONAF borehole network is to detect, locate, and characterize $M \sim 0$ microearthquakes on the NAFZ at some 5-20 km distance. This will allow us to study fault zone processes along the Marmara segment with unprecedented detail-over several orders of magnitude for the different earthquake source parameters (Bohnhoff et al. 2010). Using the existing surface station catalog and the geology at the various selected GONAF drill sites 

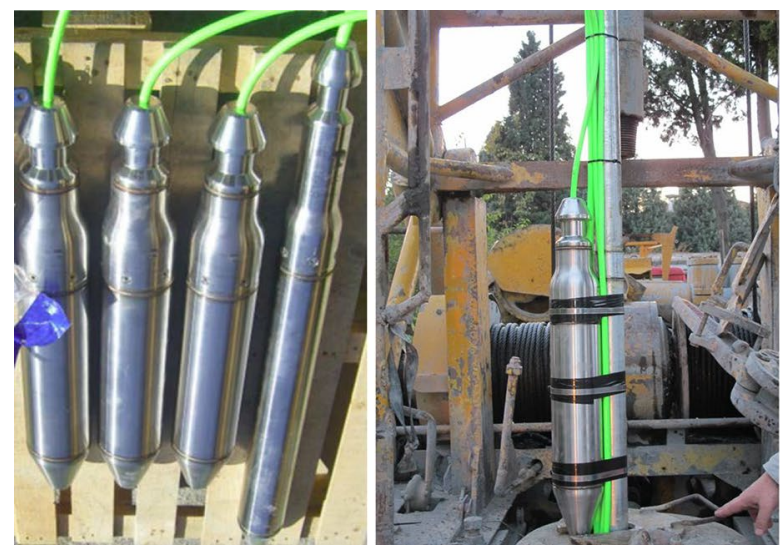

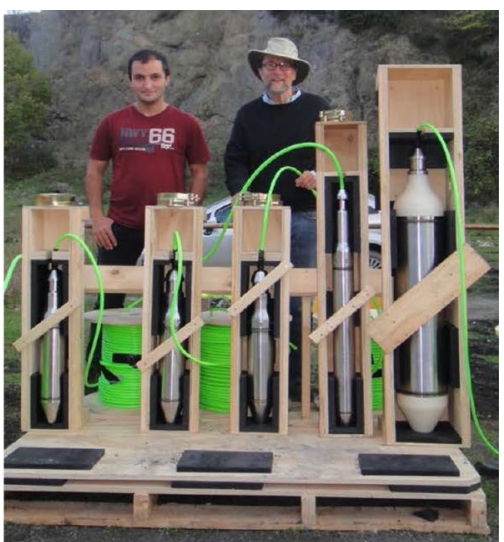

Fig. 3 Left the first GONAF station instrumentation at Tuzla borehole. Right the optimized array after the Tuzla test from left to right three levels of $1 \mathrm{~Hz}$ vertical L-4s, a combined 2 and $15 \mathrm{~Hz} 3-\mathrm{C}$, and a 3-C L4 $1 \mathrm{~Hz}$ instrument. Center the 200-m-deep vertical L-4 seismometer instrument banded to the cementing/installation pipe on its way downhole at the Tuzla site suggested that this could be achieved with 300-m-deep boreholes (Fig. 2, left). Since neither the degree of highfrequency attenuation nor the drillers' ability to control tilt at these depths was known, $1 \mathrm{~Hz}$ vertical and 2 and $15 \mathrm{~Hz}$ 3-C test seismometers were planned for installation at the initial GONAF test drill site on the Tuzla Peninsula.

Initially, a typical GONAF station was planned to consist of $1 \mathrm{~Hz}$ vertical sensors every $\sim 75 \mathrm{~m}$ along the wellbore plus a combination of 1,2 , and $15 \mathrm{~Hz} 3-\mathrm{C}$ sensors at $300 \mathrm{~m}$ depth (Fig. 3, left). This setup was to allow covering a broad frequency range, including higher frequency microearthquakes. Because their high natural frequency makes them tilt insensitive, $15 \mathrm{~Hz}$ Geospace DS2500 sensors were selected as a failsafe in case of large bottom-hole tilt. The potential tradeoffs were both more limited bandwidth and potential low signal-to-noise ratios at lower frequencies. Geospace HS-1 $2 \mathrm{~Hz}$ units were selected to cover the latter possibility and were gimbal mounted to correct for tilts as large as $\sim 15^{\circ}$ or more.

The $2 \mathrm{~Hz}$ sensors are temperature sensitive. Above $\sim 50{ }^{\circ} \mathrm{C}$, their natural frequency becomes higher than Geospace HS-1 4.5 Hz seismometers. These higher frequency units are more temperature resistant, handling temperatures as high as $150{ }^{\circ} \mathrm{C}$ with significantly less frequency drift-but again with loss of lower frequencies above about $120{ }^{\circ} \mathrm{C}$. The 2 and $15 \mathrm{~Hz} 3-\mathrm{C}$ were integrated into a single sonde placed at the bottom of the 300-m well.

The $1 \mathrm{~Hz}$ sensors-Mark Products L4 seismometerswere included both to add low frequency bandwidth and increase output signals to ensure overcoming recorder self-noise. Because of their much larger diameter, length, and tilt sensitivity compared with the other two sensor types, their selection, however, also came with a tradeoff. The issue was borehole diameter versus tilt compensation. The large diameter well required for a gimbaled $1 \mathrm{~Hz}$
3-C set seemed beyond the aims of the first test in Tuzla. Instead, three sondes of ungimbaled verticals, placed 75 , 150, and 225 meters above the bottom of the hole, were tested (Fig. 3, center). Fortunately, in the end, the drilling contractor was able to stay with borehole inclination of one degree tilt at this critical seismometer installation levels.

Together, with an additional conventional 3-C seismometer and strong-motion sensor at each GONAF wellhead, a total of 18 channels need to be recorded. The signals from them were A/D-converted at the surface, and seismic waveforms were stored and then transmitted to end users in Turkey and Germany for further processing. Accordingly, an 18-channel data logger combining these steps was designed by Guralp Company and is used for all GONAF stations. This data logger included a special, low-noise preamplifier to increase the downhole signal levels beyond the self-noise level of the logger itself. The data are sampled at 2,000 and $500 \mathrm{~Hz}$, as the GONAF downhole observatory is designed to register microearthquakes down to events as small as $M \sim-1$. Waveform recordings are transferred via underground dedicated data cables to the next accessible internet hub. In case of failure of the online data transmission system, data are always stored locally as backup for manual download at the respective site.

The results of the Tuzla test showed that the most effective sensor and recorder combination for the GONAF microearthquake objectives would be a 3-C version of the $1 \mathrm{~Hz} \mathrm{~L}-4$ seismometer. A development effort to realize the inclusion of this type of instrument in a standard GONAF installation was immediately begun. The primary consideration was accurate leveling to assure normal operation of this highly tilt sensitive sensor. The final instrument compliment for consequent NAFZ installations is shown in Fig. 3, right. 


\section{GONAF: site selection, drilling, and installation methods}

Pre-site surveys identified optimal GONAF locations, first on the basis of network geometry, information on the geological formation, and local noise conditions. Land ownership conditions, permitting, and access to electricity had thereafter also to be considered.

Information on the local geological formation was crucial to ensure that the drill holes will remain in hard rock along the entire borehole. This was to ensure good coupling of the sensors to the underlying rocks and therefore better capturing of the seismic wave field. On the Armutlu peninsula along the southern shore of the Çınarcık Basin, only a few spots of well-consolidated rocks had been reported and the geologic maps of this area were not detailed enough to confirm our choice of the drill sites. So drilling ahead was the only way to get ground truth.

The sites were then evaluated for their anthropogenic (mostly city-induced) noise, as industrially developed or highly populated areas needed to be avoided if at all possible. The selected sites were then surveyed using short-term dense seismic arrays in order to understand to what extend surrounding noise might interfere even with the much quieter downhole environment. The sites divided into ones with electrical noise, city-induced noise, and low noise. Obviously, the latter were the preferred sites.

For the first GONAF site on the Tuzla peninsula, intense effort was put into identifying potential nearby noise sources since the wider area hosts substantial industrial infrastructure as it is part of the greater Istanbul population center. In particular, the influence of a nearby transformer station as a source for $50 \mathrm{~Hz}$ noise was investigated by a profile of stations between the drill site and the transformer. Based on these recordings, power spectral density (PSD) velocity units and spectra were

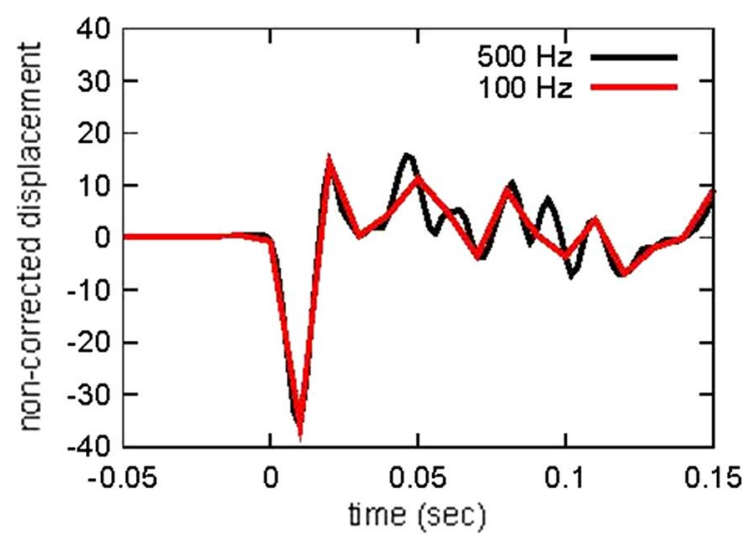

Fig. 4 Left displacement seismograms recorded by the 300-m-deep $1 \mathrm{~Hz}$ GONAF sensor of the Tesvikiye-Armutlu GONAF borehole. Right corresponding spectral data. The black lines represent origi- compared and interpreted. A major issue was the noise introduced through the power net with maxima at $50 \mathrm{~Hz}$ and multiples. This was reduced by galvanic separation from the public power net of Istanbul by using a battery power supply with a DC charger with lower noise. Furthermore, also grounding conditions were refined. With all these measures, the data quality was substantially improved and the same action was consequently taken for the other GONAF sites.

With regard to GONAF well construction, the first $50-100 \mathrm{~m}$ of the planned 300-m-deep wellbores needed to be stabilized against collapse using a metal or PVC casing. Moreover, the selected seismic sensors required absolute vertical well sections as discussed before, as well as positioning within stable rock and therefore wide borehole diameters for confident deployment and subsequent cementing.

The first of the boreholes at the Tuzla Peninsula site along the Marmara Sea shore line, approximately $30 \mathrm{~km}$ east of downtown Istanbul, was deemed a test of the GONAF PDM design. Based on the maximum sensorhousing diameter of $111 \mathrm{~mm}$, plus 4- to $12-\mathrm{mm}$ cables and a 57-mm support/cementing pipe, a minimum borehole diameter of $216 \mathrm{~mm}$ was planned. Drilling started on September 7, 2012, with a truck-mounted rig and initial 311mm wellbore diameter.

Progress was slow at around $1 \mathrm{~m} / \mathrm{h}$ or less with total mud losses in the sections above $30 \mathrm{~m}$. After sealing this interval with a $245 \mathrm{~mm}$ steel casing, drilling continued with a 216-mm-diameter 3-cone roller bit. The drilling was performed with a stabilized bottom-hole drilling assembly in order to minimize deviations from verticality. Inclination was measured during the drilling operation as a minimum in 30-m intervals. With some effort, the well was kept within a degree or two of vertical and reached its final depth of $301 \mathrm{~m}$ on October 15, 2012.

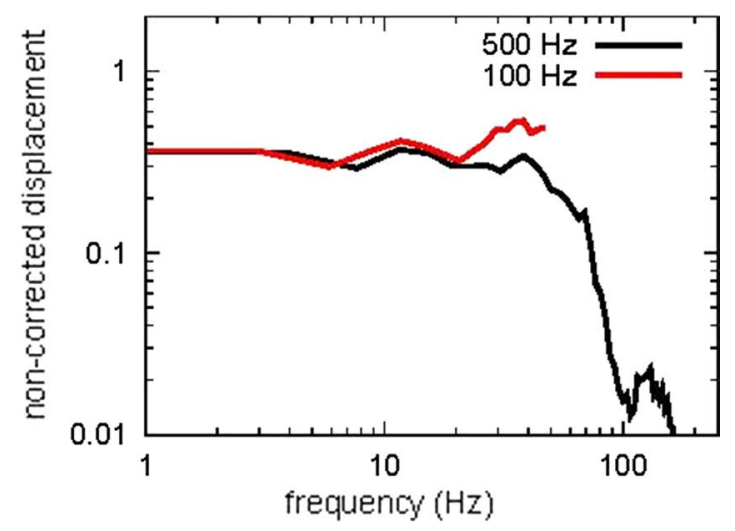

nal GONAF $500 \mathrm{~Hz}$ sampled data; red lines are the same waveform recordings but down-sampled to $100 \mathrm{~Hz}$ 
Fig. 5 Velocity recordings from an event pair recorded by the $1 \mathrm{~Hz}$ sensor placed at $300 \mathrm{~m}$ depth in the Tesvikiye-Armutlu GONAF borehole. Red and black lines represent data from $M 0$ and $M-1$ earthquakes, respectively
Fig. 6 Location map of the greater Istanbul metropolitan region in northwestern Turkey. The red line marks the Princess Islands segment as the main branch of the North Anatolian Fault Zone (NAFZ) below the eastern Sea of Marmara. Gray symbols are stations of the regional permanent networks. Yellow points are borehole locations of the GONAF project, while those with a solid frame (on the Tuzla and Armutlu peninsulas) have already been drilled and instrumented in 2012/2013 (see text for details)
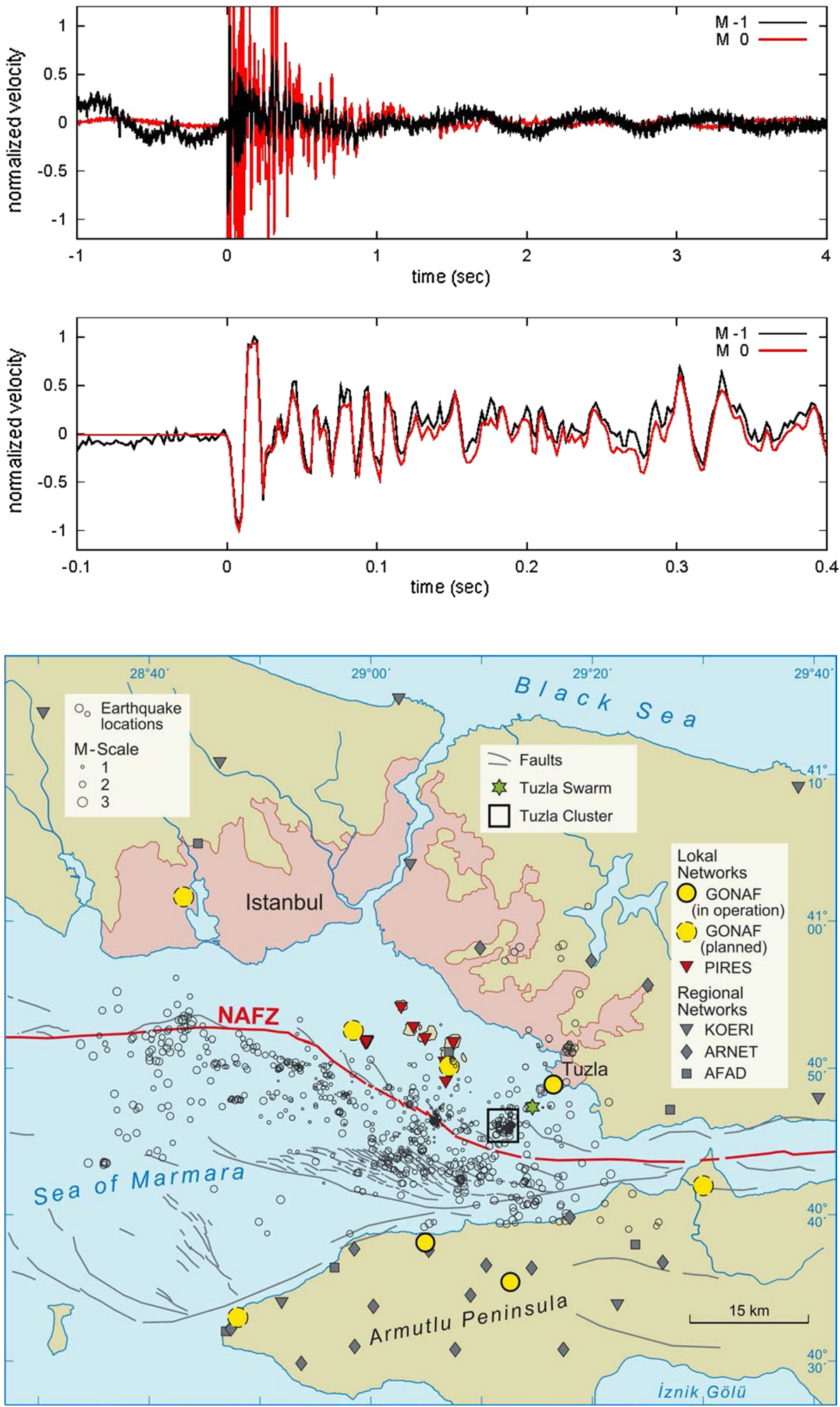

The three levels of vertical and two levels of 3-C test seismometer described in the previous section were checked prior to both deployment and cementing. The exact sensor depths had to be slightly adjusted based on structural and lithological variations along the borehole that were identified from cuttings (sampled at 2-m spacing throughout the well) as well as sonic logging (continuous). They were lowered into the hole by banding them onto the cementing trim tube as displayed in Fig. 3, center. The borehole had to be circulated periodically with drill 


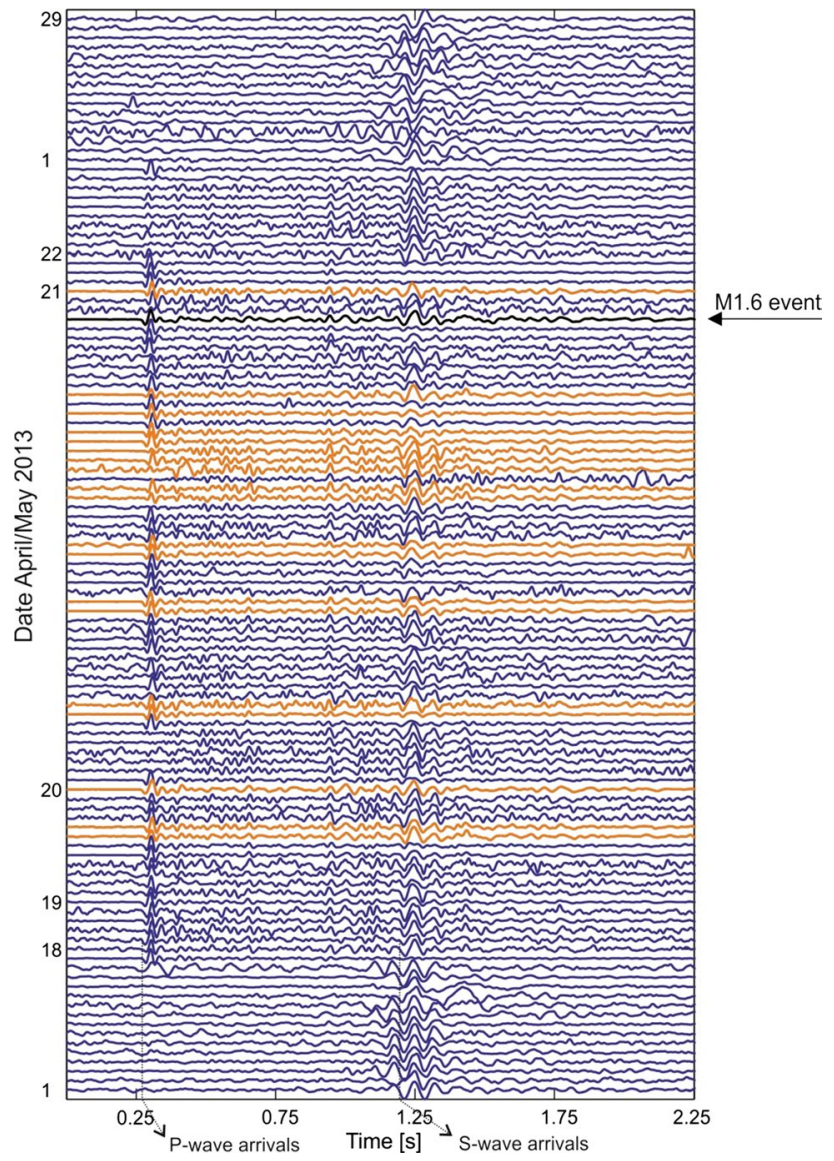

Fig. 7 Waveform recordings of the Tuzla earthquake swarm of April-May 2013. The traces shown are recordings of the $1 \mathrm{~Hz}$ vertical seismometer in the GONAF borehole at $215 \mathrm{~m}$ on the Tuzla peninsula. While only one event ( $M$ 1.6) was detected and located by the regional permanent seismic network (bold black trace), another 19 smaller-magnitude events were also detected by the closest surface station on the Princess Islands, on the southeastern-most island of Baliciada (orange traces). Using a cross-correlation technique, additional 95 earthquakes could have been detected by the GONAF Tuzla borehole station (blue traces). All events belong to one earthquake swarm within a narrow hypocentral region close to the Tuzla cluster (see Fig. 6)

mud as the installation reached target depth to ensure that the subsequent cement circulation is not blocked at the lowermost depth due to a potential mud weight increase near bottom-hole. This string was then cemented in the hole in two attempts, the first succeeding in only partially filling the well before the rig pump failed. Finally, the entire well was filled in the annulus with cement from the surface.

The results of this installation at Tuzla established the need for a 3-C $1 \mathrm{~Hz} \mathrm{~L} 4$ instrument in the standard GONAF installation (Fig. 3, right). This result then demanded a larger drilled borehole to accommodate its bigger diameter gimbals and pressure housing - as wide as $203 \mathrm{~mm}$ outer diameter. The standard borehole diameter for GONAF wells had thereafter to be increased from 216 to $356 \mathrm{~mm}$, starting with the two wells on the Armutlu peninsula drilled in 2013.

The GONAF surface recording facilities consist of a 10 -feet container hosting the 18-channel data logger, GPS antenna, communication systems, power supply, and surface short-period, long-period, and strong-motion sensors. Usually, a power grid is preferred to supply energy demands of the recording system, but it can also be powered on demand by backup batteries or on-site generators.

\section{First downhole monitoring results from the GONAF Tuzla site}

The GONAF-recorded displacement seismogram of an $M \sim 0$ event demonstrates the value of the PDM approach. The $500 \mathrm{~Hz}$ sampled seismogram in Fig. 4 was re-sampled to $100 \mathrm{~Hz}$ sampling for comparison with what might be seen on a very high quality surface station. The $100 \mathrm{~Hz}$ sampling rate, which might be sufficient for regional earthquake monitoring focusing on magnitudes above $M 2$, clearly loses many of details in the P-wave train that are needed to determine earthquake source parameters. Taking into account attenuation effects, the initial pulse width, which is around $20 \mathrm{~ms}$, suggests a source radius of smaller than $40 \mathrm{~m}$. This corresponds to a $40 \mathrm{~Hz}$ corner frequency, which is not visible in the $100 \mathrm{~Hz}$ sampled spectra (redFig. 4, right). Obviously, the high sampling rate is indispensable for microearthquake monitoring for magnitudes below $M \sim 0$.

To further demonstrate the high data quality provided from GONAF downhole recordings, waveform examples from a pair of earthquakes are shown in Fig. 5. The S-P time and signal shapes are almost identical, suggesting that these events are very closely spaced and have an almost identical source mechanism. The S-P times are about $0.3 \mathrm{~s}$, indicating the event-station distance is $\sim 2.4 \mathrm{~km}$. The coda lengths are $\sim 1$ and $\sim 3 \mathrm{~s}$, corresponding to earthquake magnitudes of $M \sim-1$ and $M \sim 0$. Evidently, the GONAF stations provide reasonably good signal-to-noise ratios for earthquake magnitudes even down to $M \sim-1$ at several kilometers distance.

At April 20, 2013, a few months after the first GONAF station was completed on the Tuzla peninsula, a local $M$ 1.6 earthquake was detected by permanent regional seismic networks and localized south of the Tuzla peninsula (Fig. 6). This event served to elaborate on the improvements provided by downhole recordings for studying the seismic activity associated with somewhat larger events.

The region in which the $M 1.6$ event occurred is close to the so-called Tuzla earthquake cluster. Here, seismicity swarms were activated two days after the $M 7.4$ Izmit 


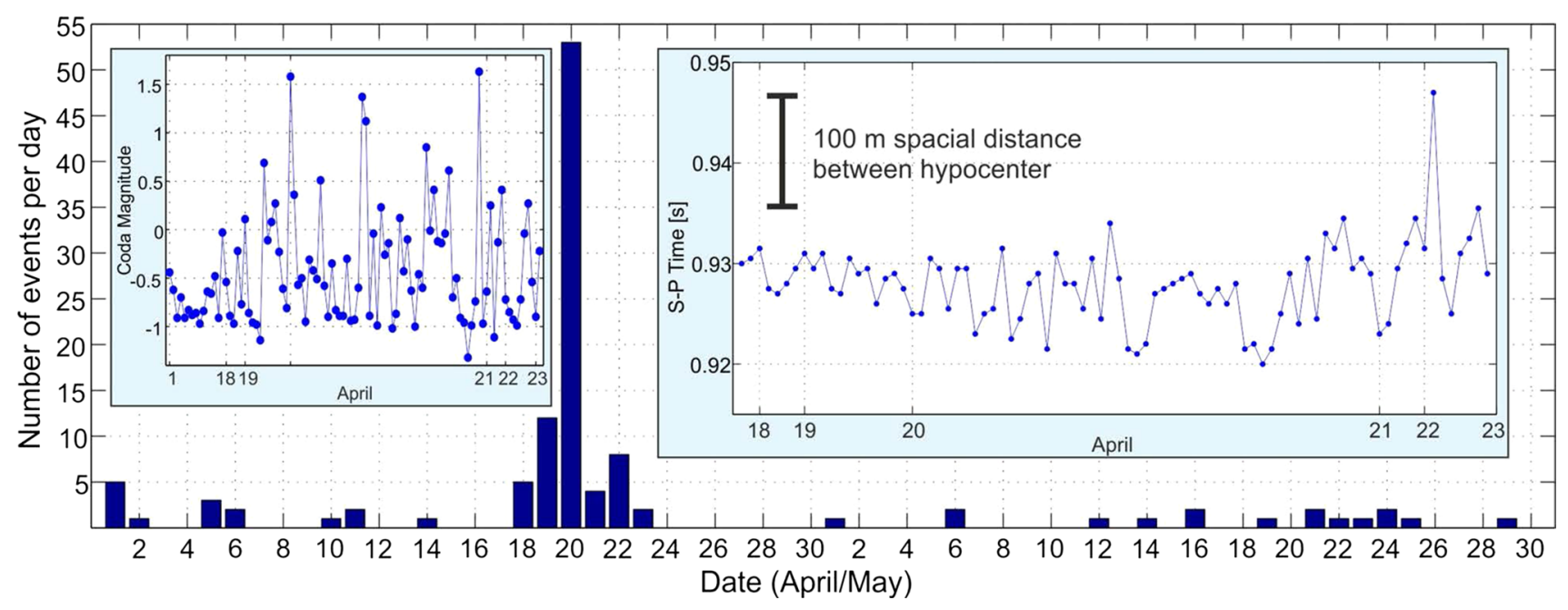

Fig. 8 Temporal evolution of the Tuzla earthquake swarm (daily event rate). While the main activity of the swarm occurred during April 18-23, 2013, several additional events with highly similar waveforms were detected during the framing 2 -month period. The

earthquake on August 17, 1999, and ever since had a nearly constant earthquake occurrence rate (Karabulut et al. 2011). Analysis of the GONAF downhole recordings revealed that the $M 1.6$ event in April was only the largest event of a whole earthquake sequence that remained undetected from surface networks. Due to the reduced noise level at the borehole sensors and the relatively short distance between sensor and the earthquake hypocenters, it was possible to detect a total of 114 additional earthquakes with smaller magnitudes framing the time of the $M 1.6$ event.

As detection algorithm, we applied a cross-correlation technique to the channel with the highest signal-to-noise ratio from all channels of the Tuzla borehole array, which is the $1 \mathrm{~Hz}$ vertical sensor at $215 \mathrm{~m}$ depth. This channel is least affected by $50 \mathrm{~Hz}$ noise, and it is the deepest one of the $1 \mathrm{~Hz}$ seismometers. The complete waveform including $\mathrm{P}$ and $\mathrm{S}$ wave coda of the $M 1.6$ event was used as a template signal, which was correlated with the continuous waveform recordings for the time period April-May 2013 by shifting it across the data in steps of one sample. The resulting cross-correlation coefficients are a measure of the similarity between the template signal and the continuous waveform recordings, with " 0 " meaning completely uncorrelated and "1" identical. When the cross-correlation coefficient exceeded a threshold of 0.4 , an earthquake was declared. This low threshold was used to ensure we obtain the largest possible number of events related to this specific swarm region during the considered time interval. In this 2-month time period, 20 of the events observed at the downhole Tuzla sensors were also recorded by closest station of the PIRES array on the Princess Islands, but at significantly lower signal-to-noise ratio (Fig. 7). upper left insert shows the temporal evolution of the earthquake magnitudes indicating a swarm-type behavior rather than a mainshockaftershock sequence. In the upper right, the S-P times are plotted, indicating no major internal migration of hypocenters

The main portion of the seismic activity lasted approximately five days from April 18 to 23, 2013. The magnitude distribution, with a mean duration (coda) magnitude of $-0.42 \pm 0.4$, resembles a typical behavior of an earthquake swarm with random magnitude distribution rather than a mainshock-aftershock sequence (Fig. 8).

The right inset in Fig. 8 shows the S-P times, which vary with a standard deviation of only $0.01 \mathrm{~s}$; hence, the movement of the earthquakes toward or away from Tuzla is limited to $\sim 80 \mathrm{~m}$. Although the variation in S-P times of $\sim 0.01 \mathrm{~s}$ is very small, the high sampling rate of 2,000 samples per second and precise relative arrival times derived from cross-correlation make it possible to achieve such high temporal resolution. In addition to S-P times, also the highly correlated waveforms (mean cross-correlation coefficient of 0.62 for events of the main swarm activity from April 18 to 23) indicate that the swarm events occur all in a similar source region and are generated by the same source mechanism.

Such seismic swarms are common for volcanic active regions where they are associated with crustal fluid migration. The seismicity of the observed Tuzla swarm might therefore also be related to upward migration of fluids and gases, in this case at branches and splay faults of the Princess Islands segment of the NAFZ (Geli et al. 2008). However, a direct link between gas emissions at the sea bottom located at the epicenter of the swarm activity and the Tuzla swarm is difficult to verify, but needs further investigation. The gas composition seems to indicate a shallower source depth than the depth of the earthquake swarm at $7 \mathrm{~km}$ and therefore might be interpreted as a decoupled process (Bourry et al. 2009). 


\section{Conclusions}

Despite the nearly ubiquitous logistical challenges and high installation cost, long-term downhole monitoring efforts can lead to ground-breaking results, contributing to the forefront of applied and fundamental research. Reduced noise levels combined with best-in class recording instrumentation and premium sensor coupling set the base for high quality seismic signal recording-ideal for microseismic applications. Permanently cementing sensors in a monitoring borehole has proven to be a long-term stable and non-deteriorating coupling method, resulting in no degradation of borehole integrity as well as pressure isolation from the atmosphere. Special attention needs to be paid to borehole verticality, particularly in regard to seismometer installations. Also, because high precision instruments come with larger dimensions, the drilled diameter has to be carefully planned in order to assure a safe installation and anchoring of the units at the desired measurement levels.

Acknowledgments The GONAF project is funded by the Helmholtz-Centre Potsdam GFZ German Centre for Geosciences, the Disaster and Emergency Management Presidency AFAD, Ankara, Turkey, the International Continental Drilling Program-ICDP, and the Helmholtz Association, Germany. We acknowledge funding within the Helmholtz Young Investigators Group "From Microseismicity to Large Earthquakes" and from the German Research Foundation within the project Bo1877/7-1. The GONAF instrumentation was assembled by the technical staff of IESE.

Open Access This article is distributed under the terms of the Creative Commons Attribution License which permits any use, distribution, and reproduction in any medium, provided the original author(s) and the source are credited.

\section{References}

Algeroy J et al (2010) Permanent monitoring: taking it to the Reservoir. Schlumberger Oilf Rev 22:34-41

Barka A, and 21 others (2002) The surface rupture and slip distribution of the 17 August 1999 Izmit Earthquake (M 7.4), North Anatolian Fault. Bull Seismol Soc Am 92(1):43-60

Bohnhoff M, Dresen G, Ellsworth WL, Ito H (2010) Passive seismic monitoring of natural and induced earthquakes: case studies, future directions and socio-economic relevance. In: Cloetingh $\mathrm{S}$, Negendank $\mathbf{J}$ (eds) New frontiers in integrated solid earth sciences. Springer, New York. doi:10.1007/978-90-481-2737-5_7

Bohnhoff M, Bulut F, Dresen G, Malin PE, Eken T, Aktar M (2013) An earthquake gap south of Istanbul. Nat Commun 4:1999. doi:10.1038/ncomms2999
Bourry C, Bertrand Chazallon B, Charlou J-L, Donval J-P, Ruffine L, Henry P, Geli L, Çagatay MN, İnan S, Moreau M (2009) Free gas and gas hydrates from the Sea of Marmara, Turkey: chemical and structural characterization. Chem Geol 264(1-4):197-206

Bulut F, Bohnhoff M, Ellsworth WL, Aktar M, Dresen G (2009) Microseismicity at the North Anatolian Fault in the Sea of Marmara offshore of Istanbul, NW Turkey. J Geophys Res 114:B09302. doi:10.1029/2008JB006244

Bulut F, Ellsworth WL, Bohnhoff M, Aktar M, Dresen G (2011) Spatiotemporal earthquake clusters along the North Anatolian Fault Zone Offshore Istanbul. Bull Seismol Soc Am 101(4):17591768. doi:10.1785/01200215

Davis E, Becker K (2007) On the fidelity of "CORK" borehole hydrologic observatory pressure records. Sci Drill 5:54-59. doi:10.2204/iodp.sd.5.09.2007

Geli L, 21 co-authors and the Marnaut Scientific Party (2008) Gas emissions and active tectonics within the submerged section of the North Anatolian Fault zone in the Sea of Marmara, Earth Planet. Sci Lett 274:34-39

Karabulut H, Schmittbuhl J, Özalaybe S, Lengliné O, Kömeç-Mutlu A, Durand V, Bouchon M, Daniel G, Bouin MP (2011) Evolution of the seismicity in the eastern Marmara Sea a decade before and after the 17 August 1999 Izmit earthquake. Tectonophysics 510(1-2):17-27

Malin PE, Blakeslee SN, Alvarez MG, Martin AJ (1989) Microearthquake imaging of the parkfield asperity. Sci Rep 244:557-559

Michelini A, McEvilly TV (1991) Seismological studies at parkfield. I. Simultaneous inversion for velocity structure and hypocenters using cubic B-splines parameterization. Bull Seismol Soc Am 81(2):524-552

National Research Council (2001) Review of earthscope integrated science. National Academy Press, Washington, DC 2001

Okada Y, Kasahara K, Hori S, Obara K, Fujiwara H, Yamamoto A (2004) Recent progress of seismic observation networks in Japan- Hi-net, F-net, K-NET and KiK-net. Earth Planets Space 56:xv-xxviii

Parsons $T$ (2004) Recalculated probability of $M \geq 7$ earthquakes beneath the Sea of Marmara, Turkey. J Geophys Res. doi:10.10 29/2003JB002667

Prevedel B, Wohlgemuth L, Henninges J, Krüger K, Norden B, Förster A, $\mathrm{CO}_{2} \mathrm{SINK}$ Drilling Group (2008) The $\mathrm{CO}_{2} \mathrm{SINK}$ boreholes for geological storage testing. Sci Drill 6:32-37. doi:10.2204/iodp.sd.6.04.2008

Rodriguez A et al (1998) Project to develop and evaluate coiled tubing and slim-hole technology. DEA 67, Ph.II, TR 98-10

Reilinger R, Toksoz N, McClusky S, Barka A (2000) 1999 Izmit, Turkey, earthquakes was no surprise. GSA Today 10(1):1-6

Stein RS, Barka A, Dieterich H-J (1997) Progressive failure ob the North Anatolian fault since 1939 by earthquake stress triggering. Geophys J Int 128:594-604

Thompson R (1985) Armored optical fiber cable. Patent No. US4523804

Zoback MD, Hickman S, Ellsworth WL, the SAFOD Science Team (2011) Scientific drilling into the San Andreas Fault Zonean overview of SAFOD's first five years. Sci Drill 11:14-28. doi:10.2204/iodp.sd.11.02.2011 